CLINICAL STUDY

\title{
Diagnosis, management and therapeutic outcome in prepubertal Cushing's disease
}

\author{
R P Dias ${ }^{1}$, A Kumaran ${ }^{1}$, L F Chan ${ }^{1}$, L Martin ${ }^{1}$, F Afshar ${ }^{2}$, M Matson ${ }^{3}$, P N Plowman ${ }^{4}$, J P Monson ${ }^{1}$, \\ G M Besser ${ }^{1}$, A B Grossman ${ }^{1}$, M O Savage ${ }^{1}$ and H L Storr ${ }^{1}$ \\ Departments of ${ }^{1}$ Endocrinology, ${ }^{2}$ Neurosurgery, ${ }^{3}$ Radiology and ${ }^{4}$ Radiotherapy, Barts and the Royal London School of Medicine and Dentistry, \\ London EC1A $7 B E$, UK
}

(Correspondence should be addressed to H L Storr who is now at William Harvey Research Institute, Centre for Endocrinology, John Vane Building, Charterhouse Square, London EC1M 6BQ, UK; Email: h.l.storr@qmul.ac.uk)

\begin{abstract}
Objectives: Cushing's disease (CD) in prepubertal children is very rare and presents important diagnostic and therapeutic challenges. We report experience of the management of this subpopulation of CD patients.

Study design/methods: Retrospective patient case note review.

Results: Between 1985 and 2008, 17 prepubertal children (13M, 4F), aged 5.7-14.1 years presented to our centre for diagnosis and management of $\mathrm{CD}$. All children had subnormal linear growth and excessive weight gain at presentation. A high proportion ( $85 \%$ of males, $75 \%$ of females) had evidence of excessive virilisation. Striae and hypertension were seen in $41 \%$ of patients. The investigation with highest sensitivity $(100 \%)$ for CD was excessive increase of serum cortisol to i.v. CRH (mean increase $113 \%)$. Pituitary imaging performed in all the patients showed poor concordance with findings at surgery $(31 \%)$. In contrast bilateral simultaneous inferior petrosal sinus sampling (BSIPSS), performed in $11 / 16$ subjects showed a high correlation with surgical findings (91\%). In 16 patients, transsphenoidal selective adenomectomy (TSS) achieved a cure rate of 44\%. However, in the 11 patients who had pre-operative BSIPSS, the cure rate was $64 \%$. Of the 16 patients, 9 patients who were not cured by TSS received external pituitary radiotherapy.

Conclusions: Prepubertal CD had distinctive features with increased frequency in males, abnormal auxology and excessive virilisation. The cortisol response to i.v. CRH administration was particularly exuberant and contributed to diagnosis. BSIPSS was much more helpful than pituitary imaging in localisation of the microadenoma and was associated with improved cure rate by TSS.
\end{abstract}

European Journal of Endocrinology 162 603-609

\section{Introduction}

Cushing's disease (CD) is caused by excess ACTH secretion by a pituitary corticotroph tumour. In all age groups, microadenomas are the most common cause. In childhood and adolescence, CD accounts for $\sim 75-80 \%$ of paediatric Cushing's syndrome cases, but is still rare (1). In children, the hypercortisolaemia of CD can cause severe morbidity, so early diagnosis, based on a series of standardised biochemical and radiological investigations, is essential (1-5).

Children with CD who are prepubertal, defined by the absence of gonadotrophin-dependent secondary sexual characteristics, comprise a rare subgroup, as most paediatric $C D$ patients are pubertal at the time of diagnosis (3). There are very few reports describing the diagnosis and management of prepubertal children with CD.

The diagnosis and management of young children with CD poses a significant challenge to the paediatric endocrinologist. Firstly, the clinical features of $\mathrm{CD}$ in children may be relatively subtle with growth failure and abnormal puberty being two of the most common features (6-8). Secondly, the microadenomas are usually very small and pituitary imaging may fail to detect the lesion $(9,10)$. In addition, transsphenoidal microadenomectomy may be technically very difficult in children and requires a highly skilled and experienced neurosurgeon $(11,12)$.

Here we review the diagnostic features, management and therapeutic outcomes of all the prepubertal $\mathrm{CD}$ patients managed in a single centre during a 23-year period.

\section{Subjects and methods}

\section{Patients}

Between 1985 and 2008, 17 prepubertal children (13 males, 4 females), aged 5.7-14.1 years with CD, were treated in the paediatric endocrine unit at St Bartholomew's and the Royal London Hospitals, London, UK. 
Puberty was staged according to the criteria of Tanner $(13,14)$. Prepubertal status in males was defined as testicular volumes $<4 \mathrm{ml}$ and in females breast development < Tanner stage 2 . Evidence of virilisation, shown by genital and/or pubic hair Tanner stage $\geq 2$, was present in $10 / 17$ patients. In all cases, however, testicular volumes or breast development were prepubertal.

\section{Clinical features and auxology}

Parental reports of timing of onset of symptoms including weight gain, change in facial appearance, fatigue, headaches and emotional lability were ascertained on direct questioning. Hypertension was defined as a diastolic or systolic blood pressure $>95$ th centile for age and sex on more than two occasions (15). Auxological observations consisted of measurement of height, height velocity and weight using standardised anthropometric techniques (16). Body mass index (BMI) was calculated and converted to SDS using the method of Cole (17). Height was converted to SDS using the method of Tanner $(16,18)$. Bone age (BA) was determined using the TW3 RUS method (TannerWhitehouse 3 radius, ulna and small bones), and BA delay was calculated as the difference between chronological age and BA (19).

\section{Diagnosis of CD}

$\mathrm{CD}$ was diagnosed on the basis of detectable $0900 \mathrm{~h}$ plasma ACTH (normal range 10-50 ng/l), loss of serum cortisol circadian rhythm (elevated sleeping $0000 \mathrm{~h}$ cortisol $>50 \mathrm{nmol} / \mathrm{l}$ ) and failure of serum cortisol to suppress to $<50 \mathrm{nmol} / \mathrm{l}$ during a low-dose dexamethasone suppression test (LDDST: $0.5 \mathrm{mg}$ every $6 \mathrm{~h}$ for $48 \mathrm{~h}$, corrected to $30 \mu \mathrm{g} / \mathrm{kg}$ per day in children $<30 \mathrm{~kg}$ ) (3). Additionally, the patients showed suppression of serum cortisol to $<50 \%$ of baseline in a highdose dexamethasone suppression test (HDDST: $2 \mathrm{mg}$ every $6 \mathrm{~h}$ for $48 \mathrm{~h}$, corrected to $120 \mu \mathrm{g} / \mathrm{kg}$ per day in children $<30 \mathrm{~kg})(3,4)$ and/or an exaggerated $(\geq 20 \%$ of baseline) rise in serum cortisol during a corticotrophin-releasing hormone $(\mathrm{CRH})$ test $(100 \mu \mathrm{g}$ human sequence recombinant i.v. CRH) (20).

\section{Pituitary imaging}

All the patients underwent pre-operative pituitary magnetic resonance imaging (MRI), as previously described (21). MRI was performed at 1.5 Tesla. T1weighted sequences were acquired in sagittal and coronal planes with a 3-mm slice thickness. After gadolinium administration, further acquisitions were made in the coronal plane; a dynamic sequence within $60 \mathrm{~s}$ of contrast and then a gradient-echo volume acquisition, reconstructed in both sagittal and axial planes. In all the cases, radiologists were blinded to the results of inferior petrosal sinus sample (IPSS). Patients had MRI within the same centre. During the study period of 23 years, MR scanners were changed twice with improved spatial resolution, most importantly in 2000.

\section{Bilateral simultaneous inferior petrosal sinus sampling}

Bilateral simultaneous inferior petrosal sinus sampling (BSIPSS) with i.v. administration of $100 \mu \mathrm{g} \mathrm{CRH}$ was introduced in our centre for paediatric patients in 1986 (22). BSIPSS was performed in $11 / 17$ patients $(65 \%)$, all with microadenomas, without complications. In a total of six patients, BSIPSS was not attempted: in two patients this was for technical reasons, another two patients presented before the introduction of the technique, one patient had a macroadenoma and one patient was too unwell due to respiratory failure. In nine children, BSIPSS was performed without sedation, but two young patients (aged 5.6 and 6.6 years) required general anaesthesia. Written informed parental consent was obtained for BSIPSS in every child.

The central to peripheral (IPS/P) ACTH ratio was defined as the highest right or left IPS value after the administration of $\mathrm{CRH}$ compared with the concurrent level in a peripheral blood sample (P). A basal or $\mathrm{CRH}-$ stimulated IPS/P ratio of $>2$ was taken as indicative of pituitary ACTH secretion (4). The interpetrosal sinus ACTH gradient (IPSG) was calculated by taking the highest IPS ACTH value (right or left) after $\mathrm{CRH}$ administration divided by the value at the same time point in the contralateral IPS. Lateralisation of ACTH secretion was defined as an IPSG of $>1.4$, while an IPSG of $<1.4$ was suggestive of a midline lesion, as previously described (23).

\section{Transsphenoidal selective adenomectomy and histological analysis}

Sixteen patients underwent transsphenoidal selective adenomectomy (TSS) as first-line treatment. Two patients underwent TSS in other centres prior to referral to our unit. In our centre, the same neurosurgeon (F A) performed TSS in 14 patients, as previously described (12). The location of the adenomas was categorised as right-sided, left-sided or midline, based on the operation notes. Parenteral hydrocortisone was given perioperatively and for a minimum of $24 \mathrm{~h}$ post-operatively. Data on histological analysis of pituitary tissue were available for all but one patient, who underwent TSS in another country.

Bilateral adrenalectomy was performed in one patient because of extreme illness with respiratory failure; this child is excluded from further analysis in the results. 


\section{Pituitary radiotherapy}

In our centre, pituitary radiotherapy (RT) is the secondline treatment for paediatric CD after unsuccessful TSS. All the patients who were not cured by TSS $(n=9)$ received external beam pituitary irradiation, with $6 \mathrm{MeV}$ photons from a linear accelerator to deliver $45 \mathrm{~Gy}$ in 25 fractions over 35 days. A three-field technique (two lateral and one superior oblique) was used to localise radiation to the pituitary, as previously described (24).

\section{Definition of cure of CD}

Post-TSS, serum cortisol levels were measured daily at $0900 \mathrm{~h}$ at least $12 \mathrm{~h}$ after the last dose of hydrocortisone (mean 2.1 days post-operatively; range 1-7 days). Cure was defined as an undetectable serum cortisol level $(<50 \mathrm{nmol} / \mathrm{l})$ (25). Cure of CD after second-line pituitary RT was defined as a mean serum cortisol on a 5-point day curve of $<150 \mathrm{nmol} / \mathrm{l}$ after discontinuation of medical therapy, in addition to a midnight serum cortisol $<50 \mathrm{ng} / \mathrm{l}$ and suppression of serum cortisol to $<50 \mathrm{nmol} / \mathrm{l}$ on the LDDST, as previously described (26).

\section{Hormone assays}

ACTH was measured using two-site chemiluminescent immunometric assays on an Immulite semi-automated analyser (DPC Ltd, Llanberis, Wales, UK), with an assay imprecision $<8 \%$ (25). Serum cortisol was determined historically on the Bayer Technicon Immuno-I automated immunoassay analyser (Bayer Diagnostics) and, since 2004, on the Roche E170 automated immunoassay analyser. Assay imprecision of both the systems has been calculated as $<6 \%$.

\section{Results}

\section{Clinical features and pubertal staging at diagnosis}

Seventy-five percent of the patients were males, which was significantly higher than expected $(P<0.01$, df 1$)$. The median age at diagnosis was 9.4 years (range 5.7-14.1) with a median length of history prior to diagnosis of 2 years (range 0.5-4.0; Table 1). At diagnosis, median height SDS was -1.8 (range -3.7 to +1.2 ) and median height velocity, calculated over a minimum period of 6 months, was $2 \mathrm{~cm} /$ year (range 0-3.4). The median BMI SDS was + 3 (range 1.9-9.2; Tables 1 and 2).

Excessive virilisation was present in 11/13 males $(85 \%)$ and $3 / 4$ females $(75 \%)$. Hirsutism was present in $50 \%$ of the patients (Table 2). BA was delayed by $>1$ year in $8 / 17(47 \%)$ patients (mean difference between chronological age and BA was -1.6 years; range -2.6 to +0.9). The presence of acne, hypertension and striae was variable and was reported in less than half of the patients (Table 2). Fatigue was present in $11 / 17$ $(65 \%)$ patients.

\section{Diagnostic tests}

All the patients demonstrated loss of serum cortisol circadian rhythm and had an elevated midnight sleeping cortisol (mean $566 \mathrm{nmol} / \mathrm{l}$; range 1961377). All the patients also had detectable $0900 \mathrm{~h}$ plasma ACTH (mean $48 \mathrm{ng} / \mathrm{l}$; range $13-125 \mathrm{ng} / \mathrm{l}$ ). During the LDDST, serum cortisol failed to suppress to $<50 \mathrm{nmol} / \mathrm{l}$ in 16/17 (94\%) patients. The only subject who suppressed to $<50 \mathrm{nmol} / \mathrm{l}$ had cyclical CD associated with a pituitary corticotroph macroadenoma. The HDDST was undertaken in 14/17 (82\%)

Table 1 Auxological features and puberty staging in 17 patients at diagnosis of Cushing's disease.

\begin{tabular}{|c|c|c|c|c|c|c|c|}
\hline & Age (years) & Sex & $\begin{array}{l}\text { Puberty stage } \\
\text { (testicular volume in } \mathrm{ml} \text { ) }\end{array}$ & Height SDS & $\begin{array}{l}\text { Height velocity } \\
\text { (cm/years) }\end{array}$ & BMI SDS & BA (year) \\
\hline 1 & 5.7 & $\mathrm{~F}$ & $\mathrm{~A} 1 \mathrm{~B} 1 \mathrm{P} 1$ & -0.2 & NA & 6.9 & 4.1 \\
\hline 2 & 6.2 & M & A1 G3 P2 (3/2) & -1.4 & NA & 9.2 & 4.6 \\
\hline 3 & 6.4 & $M$ & P2 G2 (2/2) & -1.6 & 3.4 & 5.1 & 6.0 \\
\hline 4 & 6.6 & M & A1 G2 P2 (2/2) & -3.2 & 2.5 & 3.8 & 4.8 \\
\hline 5 & 7.6 & M & P2 G1 (2/2) & -3.7 & 2.2 & 4 & 3.3 \\
\hline 6 & 8.2 & $\mathrm{M}$ & G2 P1 (2/2) & -1.5 & NA & 3 & 7.9 \\
\hline 7 & 8.4 & M & P3 G2 (1/1) & -3.5 & NA & 2.9 & 6.3 \\
\hline 8 & 8.8 & $\mathrm{M}$ & G1 P1 (3/3) & -1.1 & 0 & 3.2 & 5.8 \\
\hline 9 & 9.4 & M & P2 G2 (2/2) & 1.2 & NA & 1.9 & 9.0 \\
\hline 10 & 10.6 & $\mathrm{~F}$ & $\mathrm{~B} 1 \mathrm{P} 2 \mathrm{~A} 1$ & -1.1 & NA & 2.3 & 8.0 \\
\hline 11 & 10.8 & M & G1 P1 (2/1) & -2.8 & NA & 2.6 & 6.5 \\
\hline 12 & 11.6 & $M$ & A1 G1 P2 (2/3) & -1.6 & 0.8 & 3 & 8.6 \\
\hline 13 & 11.7 & $\mathrm{M}$ & G1 P2 (2/2) & -1.8 & 2.2 & 3.1 & 12.6 \\
\hline 14 & 11.9 & $\mathrm{~F}$ & B1 P5 A3 & -2.0 & 2.1 & 2.5 & 10.7 \\
\hline 15 & 13.6 & $\mathrm{M}$ & P3 G2 (3/3) & -3.6 & 1.2 & 2.1 & 13.0 \\
\hline 16 & 13.7 & M & P3 G3 (3/3) & -1.8 & 1.9 & 2.3 & 13.5 \\
\hline 17 & 14.1 & $\mathrm{~F}$ & A3 B1 P4 & -2.1 & 2 & 2.5 & 13.5 \\
\hline
\end{tabular}

F, female; M, male. Pubertal staging: A, auxillary hair; $G$, genitalia; $B$, breast and $P$, pubic hair. Height velocity during $\geq 0.5$ years. Numbers in parentheses indicate testicular volumes in millilitres; BMI indicates body mass index score. BA, bone age (TW3 RUS method); NA, data not available. 
Table 2 Clinical signs and symptoms in 17 Cushing's disease patients at diagnosis.

\begin{tabular}{lc}
\hline Clinical feature & Percentage $(n)$ \\
\hline Acne & $29(5)$ \\
Hypertension & $41(7)$ \\
Striae & $41(7)$ \\
Headache & $41(7)$ \\
Fatigue & $65(11)$ \\
Hirsutism & $52(9)$ \\
Emotional lability & $59(10)$ \\
\hline
\end{tabular}

Percentage of children who demonstrated the clinical sign or reported symptom at diagnosis, figure in parentheses indicates actual number of patients.

patients, with $12(87 \%)$ patients suppressing their serum cortisol to $>50 \%$ of baseline. All 17 patients underwent a CRH test and $100 \%$ of them had an increase of serum cortisol from baseline of $>20 \%$ (mean change $113 \%$; range 30-438\%).

\section{Radiological imaging studies and concordance with findings at TSS}

Pituitary MRI reported an adenoma in 10/17 (59\%) of patients. The percentage concordance of imaging with the findings at surgery was only $31 \%(5 / 16)$, including the patient with the macroadenoma. Furthermore, in $6 / 7(86 \%)$ patients who were reported to have normal imaging, a tumour was visualised during TSS. There have been some changes in neuroradiology personnel and MR technology and equipment over a 23-year period. Within our service, 8/17 (47\%) children were scanned prior to the latest scanner installation in 2000 and $2 / 8(25 \%)$ patients showed concordance with surgical findings which is similar to the overall findings.

\section{Results of BSIPSS}

BSIPSS was performed in 11/16 (69\%) patients (8M, 3F, mean age 11.0 years, range 5.7-14.1 years). Sampling for ACTH was performed from the inferior petrosal sinuses bilaterally in 9/11 patients and from both high internal jugular veins (HJV) in 2/11 (18\%) patients. The peak IPS/P or HJV/P ACTH ratio after CRH was $\geq 2$ (mean 13.2, range 2.0-28.6) in 10/11 (91\%) patients. One patient who underwent HJV sampling had a peak central to peripheral ratio post-CRH of $\leq 2$ (0.95). TSS was performed in this child as all the other biochemical investigations were entirely consistent with a diagnosis of $\mathrm{CD}$.

In 9/11 (82\%) patients, the IPSG after $\mathrm{CRH}$ was $>1.4$ (mean 9.95, range 1.7-20.8) indicating ACTH lateralisation (to the right-side in seven patients and to the left-side in two patients). In the two patients who did not demonstrate lateralisation, TSS revealed a left-sided adenoma in one case and a midline adenoma in the other.

\section{Concordance of the results of BSIPSS with findings at TSS}

In 10/11 (91\%) patients who underwent BSIPSS, the site of ACTH secretion was consistent with the position of the adenoma seen during surgery. Of note, bilateral HJV sampling correctly identified the adenoma position in both patients.

\section{Cure of CD and results of histological analysis}

An adenoma was confidently identified by the neurosurgeon during TSS in 14/16 (88\%) patients. Histological analysis confirmed a corticotroph adenoma in $8 / 15(53 \%)$ patients (Table 3 ).

Table 3 Results of pituitary imaging, bilateral simultaneous inferior petrosal sinus sampling, transsphenoidal surgery and histology.

\begin{tabular}{|c|c|c|c|c|c|c|}
\hline & MRI & $\begin{array}{l}\text { IPSS site/ } \\
\text { lateralisation }\end{array}$ & $\begin{array}{l}\text { Adenoma at } \\
\text { surgery }\end{array}$ & Histology & Treatment & Cure \\
\hline 1 & $\mathrm{~N}$ & IPS/R (under GA) & $\mathrm{R}$ & Adenoma & TSS & $Y$ \\
\hline 2 & $\mathrm{~N}$ & ND & NA & - & Adrenalectomy & $\mathrm{Y}$ \\
\hline 3 & ML & ND & Not seen & $\mathrm{N}$ & TSS RT & $\mathrm{Y}$ \\
\hline 4 & $\mathrm{~N}$ & IPS/L (under GA) & $\mathrm{L}$ & Adenoma & TSS & $Y$ \\
\hline 5 & $\mathrm{R}$ & ND & $\mathrm{R}$ & $\mathrm{N}$ & TSS RT & $Y$ \\
\hline 7 & $\mathrm{R}$ & IPS/R & $\mathrm{R}$ & $\mathrm{N}$ & TSS RT & $\mathrm{Y}$ \\
\hline 8 & $\mathrm{~L}$ & $M L$ & $\mathrm{~L}$ & $\mathrm{~N}$ & TSS RT & $\mathrm{N}$ \\
\hline 9 & $\mathrm{R}$ & ND & $\mathrm{R}$ & Adenoma & TSS RT & $\mathrm{Y}$ \\
\hline 10 & $\mathrm{~L}$ & IPS/R & $\mathrm{R}$ & $\mathrm{N}$ & TSS RT & $Y$ \\
\hline 11 & $\bar{N}$ & HJV/ML & $\mathrm{ML}$ & Adenoma & TSS & $\mathrm{Y}$ \\
\hline 12 & $\mathrm{R}$ & IPS/R & NA & NA & $\begin{array}{l}\text { TSS } \times 2, \text { RT } \\
\quad \text { (in Poland) }\end{array}$ & $\mathrm{N}$ \\
\hline 13 & $\mathrm{R}$ & IPS/L & $\mathrm{L}$ & $\mathrm{N}$ & TSS & $Y$ \\
\hline 15 & $\mathrm{~N}$ & HJV/R & $\mathrm{R}$ & $\mathrm{N}$ & TSS & $\mathrm{Y}$ \\
\hline 16 & $M L$ & ND & $\mathrm{R}$ & Adenoma & TSS RT & $Y$ \\
\hline 17 & $\mathrm{~N}$ & IPS/R & $\mathrm{R}$ & Adenoma & TSS & $\mathrm{Y}$ \\
\hline
\end{tabular}

$\mathrm{N}$, normal; L, left-sided lesion; R, right-sided lesion; ML, midline; NA, not available; ND, not done; IPS, inferior petrosal sinus sample; HJV, high jugular vein sample; TSS, transsphenoidal surgery alone; TSS $\times 2$, two transsphenoidal operations performed; TSS RT, transsphenoidal surgery and pituitary radiotherapy. 


\section{Cure by TSS}

Overall, 7/16 (44\%) patients were cured by TSS alone. One of the patients in whom TSS was unsuccessful had a pituitary macroadenoma. In the patients who underwent BSIPSS prior to TSS, 7/11 (64\%) were cured. Of the ten patients in whom BSIPSS findings concurred correctly with the surgical findings, seven (70\%) were cured.

\section{Cure by radiotherapy}

Pituitary RT was curative in 8/9 (89\%) patients. One patient responded initially to RT and was considered to be cured but then relapsed.

\section{Post-cure anterior pituitary function}

Patients were followed up for a median period of 3.2 years (range 0.18-16.7 years), after TSS or RT. GH provocation testing was performed in $11 / 15$ patients. Two patients were operated on within the last 6 months and so no GH provocation data are available. The main post-operative pituitary hormone deficiency in the patients cured by TSS alone was isolated GH deficiency (GHD) in 40\% (2/5), mean peak GH $33 \mathrm{mU} / \mathrm{l}$, range $<0.5-42.5$. One child developed GHD prior to TSS which was transient (reassessment post RT showed recovery). In the patients who underwent TSS and RT, $83 \%(5 / 6)$ had isolated GHD although this was transient in two children. Two male children who had TSS and pituitary RT, developed early puberty with a pubertal response on GnRH test and were treated successfully with GnRH analogue. In the nine patients for whom data are available, none had evidence of thyroid dysfunction following TSS alone or in combination with pituitary RT.

\section{Discussion}

We have reviewed the characteristics of diagnosis, management and long-term outcome in a prepubertal CD cohort managed in a single centre. Some features at diagnosis are worthy of comment. The predominance of males has previously been described (27). Magiakou et al. noted a similar phenomenon in a large series of children and adolescents (3). All the prepubertal CD patients presented with excessive weight gain and change in facial appearance with frequent growth failure highlighting the importance of accurate auxological assessment. Excessive virilisation in the majority of our patients was striking and has been previously reported (3). Clinical signs of hypercortisolaemia including hypertension and striae were common, as reported in a large series of patients from early childhood to late adolescence (3). However, despite the abnormal virilisation seen in most children, almost half had delayed BA. Suppression of gonadotrophin secretion has previously been described as a complication of chronic hypercortisolaemia (7).

Biochemical investigations in our patients showed a markedly increased cortisol response following $\mathrm{CRH}$ administration in all the subjects. The CRH test can therefore be of real diagnostic value in young children with CD. In a previously reported series of 51 children and adolescents, $75 \%$ showed an excessive increase in cortisol (mean 34\%) after $\mathrm{CRH}$, (3). However, this cohort was different to ours and included patients across a large age spectrum. The dose and type of CRH used was also different $(1 \mu \mathrm{g} / \mathrm{kg}$ of ovine $\mathrm{CRH})$.

Paediatric CD is predominantly caused by corticotroph microadenomas (defined as $<5 \mathrm{~mm}$ in diameter) which are usually hypodense on MRI and usually fail to enhance with gadolinium contrast (4). Although pituitary MRI is part of our pre-operative protocol, both the rate of visualisation of a tumour and concordance with the findings at TSS were low. This is comparable to the $\sim 20 \%$ correlation between MRI and surgical findings reported in a series of children and adolescents by Batista et al. (9). In adult CD, the detection rate was reported to be $56 \%$ with contrastenhanced MRI (28). The most likely explanation for this difference is the relatively smaller size of ACTH-secreting tumours in children. There have been improvements in MR technology, particularly over the last 15 years with markedly enhanced spatial resolution. Improved imaging techniques have reported higher detection rates in children, most importantly reducing falsenegative results (9). Within our series, concordance between MR findings and surgery remained constant during the duration of the study.

In contrast, BSIPSS was, in our experience, highly informative with identification of the site of ACTH secretion showing 91\% concordance with surgical findings. Our localisation rates in this group compare favourably with the large paediatric series from NIH, which reported $60 \%$ concordance between BSIPSS and operation findings in patients showing lateralisation (29). Furthermore, localisation of tumour site by BSIPSS appears to improve cure rate by TSS. In experienced hands, as evidenced by our results, BSIPSS is feasible and can be performed without complications in children. Performance of BSIPSS under general anaesthetic (GA) has been reported to give valid results (29). In the two patients in our series where BSIPSS was performed under GA, IPS/P and IPSG ratios were conclusive. Our cure rate from TSS in this prepubertal group was less $(44 \%)$ than in all our paediatric CD patients grouped together $(65 \%)$. This probably reflects the technical difficulty of complete removal of very small microadenomas. Differences between the percentage cure and positive histological evidence of a microadenoma have previously been reported (29). Overall, our results for cure following TSS compare favourably with other published paediatric and adult series $(8,30-32)$. 
TSS in young children is complicated by the small size of the adenomas, a small pituitary fossa and lack of sphenoid sinus aeration in some cases, as the sphenoid sinus does not achieve adult pneumatisation until approximately age 12 years. A highly skilled neurosurgeon is more likely to achieve a successful surgical outcome (11). We accept that over a 23-year period the accumulated experience of the surgeon may have influenced our results.

Post-therapeutic anterior pituitary function in children and adolescents following TSS alone and in combination with pituitary RT shows that isolated GHD is the most common anterior pituitary hormone defect seen, occurring in 56 and $83 \%$ respectively, although this can be transient $(10,33)$. Our results are comparable to this. Other anterior pituitary defects appear to be much less common.

In conclusion, presentation of $\mathrm{CD}$ in prepubertal children can be subtle with growth failure, weight gain and change in appearance being the most common presenting features. Diagnosis requires careful investigation, ideally in an experienced centre. The marked $\mathrm{CRH}$ response in this subgroup of paediatric patients was notable and of diagnostic value. Pituitary imaging correctly identified the microadenoma in only a low percentage of patients, but we believe this should remain as part of the investigation protocol. Although BSIPSS can be technically demanding and required the skill of an experienced radiologist, it was highly informative in terms of tumour localisation and appeared to contribute to optimal surgical outcome and cure.

\section{Declaration of interest}

The authors declare that there is no conflict of interest that could be perceived as prejudicing the impartiality of the research reported.

\section{Funding}

This work did not receive any specific grant from any funding agency in the public, commercial or not-for-profit sector.

\section{Acknowledgements}

We would like to thank Dr Jane Evanson, Consultant Neuroradiologist at Barts and the London NHS Trust for her advice regarding MRI techniques.

\section{References}

1 Magiakou MA \& Chrousos GP. Cushing's syndrome in children and adolescents: current diagnostic and therapeutic strategies. Journal of Endocrinological Investigation 200225 181-194.

2 Weber A, Trainer PJ, Grossman AB, Afshar F, Medbak S, Perry LA, Plowman PN, Rees LH, Besser GM \& Savage MO. Investigation, management and therapeutic outcome in 12 cases of childhood and adolescent Cushing's syndrome. Clinical Endocrinology 1995 43 19-28.
3 Magiakou MA, Mastorakos G, Oldfield EH, Gomez MT, Doppman JL, Cutler GB Jr, Nieman LK \& Chrousos GP. Cushing's syndrome in children and adolescents. Presentation, diagnosis, and therapy. New England Journal of Medicine 1994331 629-636.

4 Newell-Price J, Trainer P, Besser M \& Grossman A. The diagnosis and differential diagnosis of Cushing's syndrome and pseudoCushing's states. Endocrine Reviews 199819 647-672.

5 Storr HL, Chan LF, Grossman AB \& Savage MO. Paediatric Cushing's syndrome: epidemiology, investigation and therapeutic advances. Trends in Endocrinology and Metabolism 200718 167-174.

6 Greening JE, Storr HL, McKenzie SA, Davies KM, Martin L, Grossman AB \& Savage MO. Linear growth and body mass index in pediatric patients with Cushing's disease or simple obesity. Journal of Endocrinological Investigation 200629 885-887.

7 Dupuis CC, Storr HL, Perry LA, Ho JT, Ahmed L, Ong KK, Dunger DB, Monson JP, Grossman AB, Besser GM \& Savage MO. Abnormal puberty in paediatric Cushing's disease: relationship with adrenal androgen, sex hormone binding globulin and gonadotrophin concentrations. Clinical Endocrinology 200766 838-843.

8 Devoe DJ, Miller WL, Conte FA, Kaplan SL, Grumbach MM, Rosenthal SM, Wilson CB \& Gitelman SE. Long-term outcome in children and adolescents after transsphenoidal surgery for Cushing's disease. Journal of Clinical Endocrinology and Metabolism 199782 3196-3202.

9 Batista D, Courkoutsakis NA, Oldfield EH, Griffin KJ, Keil M, Patronas NJ \& Stratakis CA. Detection of adrenocorticotropinsecreting pituitary adenomas by magnetic resonance imaging in children and adolescents with Cushing disease. Journal of Clinical Endocrinology and Metabolism 200590 5134-5140.

10 Storr HL, Afshar F, Matson M, Sabin I, Davies KM, Evanson J, Plowman PN, Besser GM, Monson JP, Grossman AB \& Savage MO. Factors influencing cure by transsphenoidal selective adenomectomy in paediatric Cushing's disease. European Journal of Endocrinology 2005152 825-833.

11 Kanter AS, Diallo AO, Jane JA Jr, Sheehan JP, Asthagiri AR, Oskouian RJ, Okonkwo DO, Sansur CA, Vance ML, Rogol AD \& Laws ER Jr. Single-center experience with pediatric Cushing's disease. Journal of Neurosurgery 2005103 413-420.

12 Joshi SM, Hewitt RJ, Storr HL, Rezajooi K, Ellamushi H, Grossman AB, Savage MO \& Afshar F. Cushing's disease in children and adolescents: 20 years of experience in a single neurosurgical center. Neurosurgery 200557 281-285.

13 Marshall WA \& Tanner JM. Variations in the pattern of pubertal changes in boys. Archives of Disease in Childhood 197045 13-23.

14 Marshall WA \& Tanner JM. Variations in pattern of pubertal changes in girls. Archives of Disease in Childhood 1969 44 291-303.

15 Falkner B \& Daniels SR. Summary of the fourth report on the diagnosis, evaluation, and treatment of high blood pressure in children and adolescents. Hypertension 200444 387-388.

16 Tanner JM, Whitehouse RH \& Takaishi M. Standards from birth to maturity for height, weight, height velocity, and weight velocity: British children, 1965. II. Archives of Disease in Childhood 196641 613-635.

17 Cole TJ, Freeman JV \& Preece MA. Body mass index reference curves for the UK, 1990. Archives of Disease in Childhood 199573 25-29.

18 Tanner JM \& Buckler JM. Revision and update of TannerWhitehouse clinical longitudinal charts for height and weight. European Journal of Pediatrics 1997156 248-249.

19 Tanner JM, Healy M \& Goldstein H. Assessment of Skeletal Maturity and Prediction of Adult Height (TW3 Method), London: WB Saunders, Harcourt Publishers Ltd, 2001.

20 Newell-Price J, Morris DG, Drake WM, Korbonits M, Monson JP, Besser GM \& Grossman AB. Optimal response criteria for the human CRH test in the differential diagnosis of ACTH-dependent Cushing's syndrome. Journal of Clinical Endocrinology and Metabolism 200287 1640-1645. 
21 Lienhardt A, Grossman AB, Dacie JE, Evanson J, Huebner A, Afshar F, Plowman PN, Besser GM \& Savage MO. Relative contributions of inferior petrosal sinus sampling and pituitary imaging in the investigation of children and adolescents with ACTH-dependent Cushing's syndrome. Journal of Clinical Endocrinology and Metabolism 2001 86 5711-5714.

22 Hauffa BP, Stolecke H \& Schulte HM. Cushing disease: successful preoperative lateralization of an ACTH-producing pituitary microadenoma by simultaneous bilateral inferior petrosal venous sinus sampling with corticotropin-releasing hormone stimulation. European Journal of Pediatrics 1986145 559-562.

23 Oldfield EH, Doppman JL, Nieman LK, Chrousos GP, Miller DL, Katz DA, Cutler GB Jr \& Loriaux DL. Petrosal sinus sampling with and without corticotropin-releasing hormone for the differential diagnosis of Cushing's syndrome. New England Journal of Medicine $1991325897-905$.

24 Howlett TA, Plowman PN, Wass JA, Rees LH, Jones AE \& Besser GM. Megavoltage pituitary irradiation in the management of Cushing's disease and Nelson's syndrome: long-term follow-up. Clinical Endocrinology 198931 309-323.

25 Trainer PJ, Lawrie HS, Verhelst J, Howlett TA, Lowe DG, Grossman AB, Savage MO, Afshar F \& Besser GM. Transsphenoidal resection in Cushing's disease: undetectable serum cortisol as the definition of successful treatment. Clinical Endocrinology 199338 $73-78$.

26 Storr HL, Plowman PN, Carroll PV, Francois I, Krassas GE, Afshar F, Besser GM, Grossman AB \& Savage MO. Clinical and endocrine responses to pituitary radiotherapy in pediatric Cushing's disease: an effective second-line treatment. Journal of Clinical Endocrinology and Metabolism 200388 34-37.

27 Storr HL, Isidori AM, Monson JP, Besser GM, Grossman AB \& Savage MO. Prepubertal Cushing's disease is more common in males, but there is no increase in severity at diagnosis. Journal of Clinical Endocrinology and Metabolism $2004893818-3820$.
28 Kucharczyk W, Bishop JE, Plewes DB, Keller MA \& George S. Detection of pituitary microadenomas: comparison of dynamic keyhole fast spin-echo, unenhanced, and conventional contrastenhanced MR imaging. AJR. American Journal of Roentgenology $1994163671-679$.

29 Batista D, Gennari M, Riar J, Chang R, Keil MF, Oldfield EH \& Stratakis CA. An assessment of petrosal sinus sampling for localization of pituitary microadenomas in children with Cushing disease. Journal of Clinical Endocrinology and Metabolism 200691 221-224.

30 Leinung MC, Kane LA, Scheithauer BW, Carpenter PC, Laws ER Jr \& Zimmerman D. Long term follow-up of transsphenoidal surgery for the treatment of Cushing's disease in childhood. Journal of Clinical Endocrinology and Metabolism $1995 \mathbf{8 0}$ 2475-2479.

31 Styne DM, Grumbach MM, Kaplan SL, Wilson CB \& Conte FA. Treatment of Cushing's disease in childhood and adolescence by transsphenoidal microadenomectomy. New England Journal of Medicine 1984310 889-893.

32 Fomekong E, Maiter D, Grandin C \& Raftopoulos C. Outcome of transsphenoidal surgery for Cushing's disease: a high remission rate in ACTH-secreting macroadenomas. Clinical Neurology and Neurosurgery $2009111442-449$.

33 Chan LF, Storr HL, Plowman PN, Perry LA, Besser GM, Grossman AB \& Savage MO. Long-term anterior pituitary function in patients with paediatric Cushing's disease treated with pituitary radiotherapy. European Journal of Endocrinology 2007 156 477-482.

Received 1 September 2009

Accepted 29 September 2009 